\title{
Punctuality Improvement in Australian Rail Freight Network by Transit Time Management
}

\author{
Hadi Ghaderi ${ }^{*}$ \\ Mohamamd-Reza Namazi-Rad ${ }^{2}$ \\ Payam Mokhtarian $^{2}$ \\ Jiangang Fei ${ }^{1}$ \\ Stephen Cahoon ${ }^{1}$ \\ Tin Kin $\mathrm{Ho}^{2}$
}

\begin{abstract}
With rapid development in product globalization and just-in-time production over the last two decades, area-specific reliable, responsive and customeroriented rail freight services are in demand and are of increasing interest. Having a proper understanding of underlying factors in the evaluation of the quality of rail freight services is a key challenge in the short-term and long-term regional and metropolitan freight mobility planning, particularly within the context of a competitive rail freight market as in Australia. Among the fundamental attributes of rail freight services, transit time and reliability/punctuality are of utmost importance, which also tend to be inevitably correlated. This paper discusses the potential opportunities for service improvement in the Australian non-bulk interstate network through managing the underlying factors. The paper also addresses the conditions under which these factors can be combined to enhance the utilisation and efficiency of rail freight services in the national rail infrastructure.
\end{abstract}

\section{Key words: Freight Service; Reliability; Rail Freight; Transit Time; Truncated Distribution}

\section{Introduction}

Freight transport is a key element of growth and competitiveness for the Australian economy. The Australian domestic freight task measured 521 billion tonne kilometers in 2007, with 35\% carried by road, $40 \%$ by rail and $25 \%$ by coastal shipping. Only a very small volume (of less than 0.1 per cent) of mainly high value freight was carried by air ${ }^{1}$. Of interest is that during 2006-07, tonne kilometers by rail exceeded road due to high average haul distances ${ }^{2}$. The domestic freight task, which has doubled in size over the past 20 years, has an average growth of $3.5 \%$ per annum $^{3}$. BITRE's projections ${ }^{4}$ suggest that this trend will continue, albeit with slightly slower growth into the future of approximately 3\% per annum between 2005 and 2030.

Due to the size of the Australian land mass and the dispersed locations of industrial activities and consumer markets, non-bulk freight travels vast interstate distances to arrive at the point of

\footnotetext{
${ }^{1}$ National Centre for Ports and Shipping, Australian Maritime College, TAS 7248, Australia,

${ }^{2}$ SMART Infrastructure Facility, University of Wollongong, Wollongong, NSW 2522, Australia

"Corresponding author: Hadi Ghaderi hghaderi@amc.edu.au

http://dx.doi.org/10.14453/isngi2013.proc.18
} 
consumption, which can affect the quality of freight service as the result of longer and more variable transit times. However, there are also other attributes that impact on the quality of freight services. Shippers, for example, make transport decisions based on multiple freight service attributes such as the freight rate, transit time, reliability and availability of service. Hence, for Logistics Service Providers (LSPs) such as Australian rail operators, understanding which attributes are more influential in the shippers' choice of transport mode may be a key determinant of attracting contestable trade. Recently, freight customers of Australian shippers have indicated that long transit time and low punctuality levels are their key concerns impacting on their decision to use rail for interstate intermodal freight movements ${ }^{5}$. This is supported by the view of the Australian freight forwarding industry that broadly delineates freight according to its transit time, reliability and/or other special requirements ${ }^{4}$. This paper quantitatively investigates the trade-offs between transit time and reliability and examines how reliability can be improved by managing the transit time. The remainder of this paper is organised as follows. In Section 2, a review of the Australian intermodal freight industry is presented. Particular attention is paid to the Australian inter-state intermodal freight service where modal competition is more pronounced. The research method is explained in Section 3. Section 4 presents a case study of the Sydney-Melbourne rail freight service. Analysis is provided and conclusions are drawn in Section 5.

\section{Research Background}

The freight sector is a substantial contributor to the Australian economy. It generates and facilitates economic growth and employment. The total value of the intermodal supply chains accounts for approximately $2 \%$ of Australia's gross domestic product ${ }^{6}$. In the non-bulk freight sector, the interstate corridors comprise $61 \%$ of the total value, international chains $34 \%$, and intrastate chains $5 \%^{7}$. Intermodal rail freight is segmented into two major interstate freight corridors in Australia, the North-South corridor that moves freight along the eastern coast between Melbourne, Sydney and Brisbane and the East-West corridor that moves freight between the eastern states across to Adelaide in South Australia and then Perth in Western Australia.

According to the Australasian Railway Association (ARA) ${ }^{8,9}$, in regard to the inter-capital rail freight segment, at the normal expected levels of efficiency, an 'efficient rail' system should provide a significantly lower cost freight transport option than road on all corridors. More specifically, $\mathrm{ARA}^{8}$ suggests these costs to be $30 \%$ lower on the North-South corridor and $50 \%$ on the East-West corridor. Interestingly, shippers have also highlighted that, at present, rail is generally cheaper relative to road on many line haul routes (especially east-west movements) and have indicated their desire to increase the use of rail for intermodal freight movements ${ }^{10}$. However, such cost savings can be offset by longer transit times and poor reliability of the rail service $^{10}$. A study conducted by Ref. 5 found that time sensitivity and reliability are of greater importance to freight forwarders than price or cost effectiveness in Australia. BITRE ${ }^{4}$ states that with no change in relative input costs, and in the absence of a solution to some of rail's logistic difficulties relative to road, the long-term decline of rail's share of the interstate freight market is unlikely to change.

In the international context from the perspectives of shippers and service providers, there has been increasing attention on freight mode choice and the identification of factors influencing the 
choice of transport mode ${ }^{11,12,13,14}$. Research suggests there has been an increasing demand for reliability rather than other freight service attributes such as price and transit time ${ }^{15}$. Poor reliability and long transit times are regarded as the major reasons for the low use of rail in both North-South and East-West corridors. ARA $^{9}$ explains that the inability of rail to provide timely and reliable services has effectively resulted in it no longer being a viable option for $65-75 \%$ of the North-South freight task ${ }^{9}$. Rail service performance levels on the North-South corridor are the major constraint for rail achieving a greater modal share, despite its discounted price relative to $\operatorname{road}^{8}$.

\section{Research Method}

This paper also investigates the impact of reducing transit time on train punctuality. Punctuality is one of the often used reliability performance measures in railway systems ${ }^{16}$. Train punctuality is usually related to deviations, primarily negative, from the timetable. Punctuality is often used as a discrete measurement related to a predefined level of accepted deviation ${ }^{17}$. To sufficiently research punctuality, having a data set is essential. However, detailed and precise data on non-bulk train services in interstate networks are not publicly available. Hence, this section presents the research method for developing the data set as well as the approach for investigating the impact of transit time reduction on train punctuality. The assumption that the transit time follows Poisson distributions have been used in various studies ${ }^{18-22}$. Assuming ' $\mu$ ' to denote the mean transit time while the scheduled transit time is denoted by $t_{s}$ and the maximum transit time is $t_{\operatorname{Max}}$. Here we consider the minimum transit time (denoted by $t_{\text {Min }}$ ) to be no less than the scheduled transit time. Then, we apply a two-side truncated Poisson distribution for the freight transit time.

When $X$ denotes a discreet random variable with probability density function of $f(x)=\operatorname{Pr}(X=x)$, the two-side $\left(t_{\text {Min }}, t_{\text {Max }}\right)$-truncated function is:

$$
g(x)=f\left(X=x \mid t_{\text {Min }} \leq X \leq t_{\text {Max }}\right)=\operatorname{Pr}\left(X=x \mid t_{\text {Min }} \leq X \leq t_{\text {Max }}\right)=\frac{f^{*}(x)}{\operatorname{Pr}\left(X \leq t_{\text {Max }}\right)-\operatorname{Pr}\left(X<t_{\text {Min }}\right)},
$$

where $f^{*}(x)=f(x)$ for all $t_{\operatorname{Min}} \leq X \leq t_{\operatorname{Max}}$. Note that, $g(X)$ has the same support as $f^{*}(x)$. The function $g(x)$ is a probability density function with $t_{\operatorname{Min}} \leq X \leq t_{\operatorname{Max}}$ support, and the total probability over the support becomes ' 1 ,'23.

$$
\begin{gathered}
\sum_{x=t_{\text {Min }}}^{t_{\text {Max }}} g(x)=\sum_{x=t_{\text {Min }}}^{t_{\text {Max }}} \operatorname{Pr}\left(X=x \mid t_{\text {Min }} \leq X \leq t_{\text {Max }}\right)=\frac{1}{\operatorname{Pr}\left(X \leq t_{\text {Max }}\right)-\operatorname{Pr}\left(X<t_{\text {Min }}\right.} \sum_{x=t_{\text {Min }}}^{t_{\text {Max }}} f^{8}(x) \\
=\frac{\operatorname{Pr}\left(X \leq t_{\text {Max }}\right)-\operatorname{Pr}\left(X<t_{\text {Min }}\right)}{\operatorname{Pr}\left(X \leq t_{\text {Max }}\right)-\operatorname{Pr}\left(X<t_{\text {Min }}\right)}=1 .
\end{gathered}
$$

Here, we assume that $x$ follows a Poisson distribution with parameter $\lambda(X \sim P(\lambda))$. Then,

$$
f(x)=\frac{e^{-\lambda} \lambda^{x}}{x !} ; x=0,1,2, \ldots
$$

Thus, the two-side $\left(t_{\text {Min }}, t_{\text {Max }}\right)$-truncated Poisson distribution is:

$$
g(x)=\frac{1}{\operatorname{Pr}\left(X \leq t_{M a x}\right)-\operatorname{Pr}\left(X<t_{M i n}\right)} \cdot \frac{e^{-\lambda_{\lambda} x}}{x !} ; x=t_{\operatorname{Min}}, t_{\operatorname{Max}}+1, \ldots, t_{M a x}-1, t_{\operatorname{Max}} .
$$


The cumulative distribution function of the two-side $\left(t_{\text {Min }}, t_{\text {Max }}\right)$ truncated Poisson distribution is defined as:

$$
\boldsymbol{G}\left(x^{*}\right)=\sum_{x=t_{\text {Min }}}^{x^{*}} g(x)
$$

In rail service scheduling, service is considered as punctual if the train arrives before a certain time (denoted by $t_{p}$ ). Based on this assumption, the probability of reliable service is:

$$
\boldsymbol{G}\left(t_{p}\right)=\sum_{y=t_{\text {Min }}}^{t_{p}} g(x)
$$

By reducing the average transit time, the probability of the reliable freight services can be computed by (6). In the next section, the cumulative probabilities are presented using a graph based on the empirical analysis of the Sydney-Melbourne rail freight route.

\section{The case of Sydney-Melbourne rail freight service}

To empirically investigate the research objective, the Sydney-Melbourne route has been chosen for two main reasons, a) the high concentration of economic activities between the two largest Australian metropolitan areas, and b) the shorter transit time and time sensitivity of this route as compared with other pair-cities. According to BITRE ${ }^{24}$ the mean of actual transit times for this particular route is 14.5 hours, while the freight train is scheduled to arrive in 13.6 hours. The scheduled and actual transit time indicator is the average timetabled transit time of trains that operated in the last week of June of each year. For this paper, the most recent data available is from 2009-10. In freight train timetabling there is an acceptable marginal time window around the scheduled arrivals. If a train arrives within that interval, it is considered as providing a punctual service.

In this study an interval of 30 minutes is assumed. To develop the probability function for the reduced transit time scenario we take the same mean of scheduled time, where the actual mean transit time has been reduced by 30 minutes. Figure 1 presents the results of developing the train arrival distribution functions and the truncated versions for the actual (based on ARTC records) and reduced scenarios.
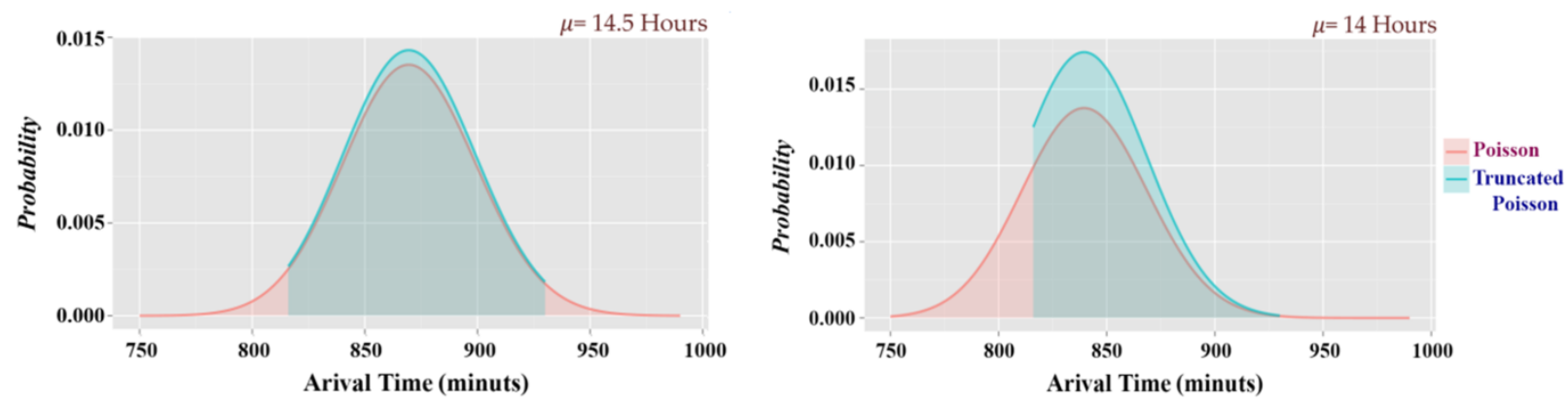

Figure 1. Simulated distribution for the train transit time (Sydney-Melbourne rail corridor).

Figure 2 shows the probability of the arrival time to fall within the punctual interval (between 13.6 hours and 14.1 hours) by marginally reducing the transit time. As shown in Figure 2 the probability of the reliability increases to approximately $40 \%, 60 \%$ and $90 \%$ when the average 
transit times are reduced by 30,60 and 90 minutes, respectively. It must be noted that, the probability of punctuality in the actual case is around $14 \%$.

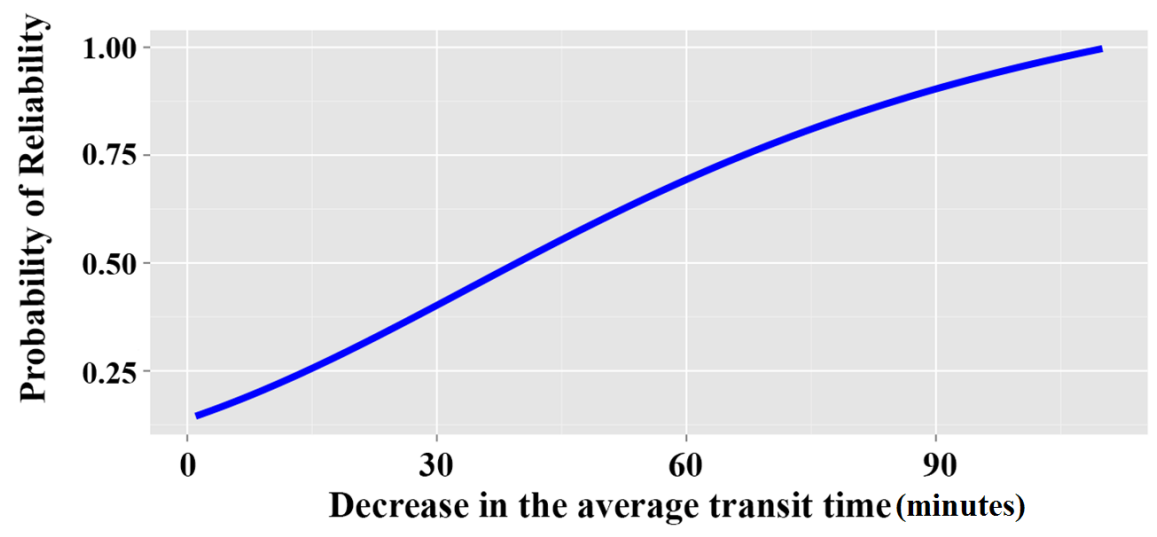

Figure 2. Plot demonstration of cumulative reliability by reducing the average transit time.

\section{Concluding remarks}

To investigate the impact of reducing transit time on train punctuality, we developed an arrival distribution function for both actual and reduced transit time scenarios. After truncating the cumulative reliability functions, the changes in service punctuality were compared. The marginal difference of train arrival reliability was then presented as the result of reducing the transit time. The results of case study show that a marginal reduction in transit time can significantly improve the service reliability. However, the trade-off between reduced transit time and the associated cost is not in the scope of this paper.

Another unique contribution of this paper is the development of a data set through basic arrival and scheduled times. This approach has been enhanced by truncating the developed data set for better analysis. Investigating the shippers' perception on changes in transit time and reliability is an interesting area for further research. However, according to the available literature on factors influencing the choice of transport mode, the improvement in reliability offsets the marginal change in transit time from the perspective of shippers.

\section{References}

${ }^{1}$ Bureau of Transport and Regional Economics, Freight Measurement and Modelling in Australia, Report 112, BTRE, Canberra ACT, 2006.

${ }^{2}$ ARTC, Annual Report, 2006.

${ }^{3}$ Bureau of Infrastructure, Transport and Regional Economics, Australian Transport Statistics Yearbook 2007, BITRE, Canberra ACT, 2008.

${ }^{4}$ Bureau of Infrastructure, Transport and Regional Economics, Road and rail freight: competitors or complements?, BITRE, Canberra ACT, 2009.

${ }^{5}$ Ernst \& Young, North-South Rail Corridor Study, Executive Report, Commissioned by the Department of Transport and Regional Services, 2006.

${ }^{6}$ Infrastructure Australia, National land Freight Strategy, IA, Canberra, ACT, 2011. 
${ }^{7}$ Booz \& Co., "Capacity Constraints \& Supply Chain Performance - Intermodal”, Working Paper \#1 - Understanding the Intermodal supply chain, National Transport Commission, Melbourne VIC, 2008.

${ }^{8}$ Australasian Railway Association, The future of Freight, Canberra ACT, 2005.

${ }^{9}$ Australasian Railway Association, National Freight Strategy-The role of Rail, Canberra ACT, 2010.

${ }^{10}$ National Transport Commission, Freight rail productivity review-Final position paper, Melbourne VIC, 2009.

${ }^{11}$ Shinghal, N., and Fowkes, T., "Freight Mode Choice and Adaptive Stated Preferences", Transportation Research Part E: Logistics and Transportation Review, Vol. 38, No. 5, 2002, pp. 367-78. http://dx.doi.org/10.1016/S1366-5545(02)00012-1

${ }^{12} \mathrm{Lu}, \mathrm{C}-\mathrm{S}$. , "The Impact of Carrier Service Attributes on Shipper-Carrier Partnering Relationships: A Shipper's Perspective", Transportation Research Part E: Logistics and Transportation Review, Vol. 39, No. 5, 2003, pp. 399-415. http://dx.doi.org/10.1016/S13665545(03)00015-2

${ }^{13}$ Danielis, R., Marcucci, E., and Rotaris, L., "Logistics Managers' Stated Preferences for Freight Service Attributes", Transportation Research Part E: Logistics and Transportation Review, Vol. 41, No. 3, pp. 201-215, 2005. http://dx.doi.org/10.1016/j.tre.2004.04.003

${ }^{14}$ Meixell, M.J., and Norbis, M., "A Review of the Transportation Mode Choice and Carrier Selection Literature", International Journal of Logistics Management, Vol. 19, No. 2, pp. 2008, pp. 183 - 211.

${ }^{15}$ Bolis, S., and Maggi, R., "Adaptive stated preference analysis of shippers' transport and logistics choice", Proceedings of the 8th World Conference of Transport Research. Pergamon, Elsevier Science, The Netherlands, 2010.

${ }^{16}$ Vromans, M., Reliability of Railway Systems, PhD thesis, Erasmus University Rotterdam, The Netherlands, 2005.

${ }^{17}$ Olsson, N.O.E., and Haugland, H., "Influencing factors on train punctuality $\square$ results from some, Norwegian studies", Transport Policy, Vol. 11, No. 4, 2004, pp. $387 \square 397$. http://dx.doi.org/10.1016/j.tranpol.2004.07.001

${ }^{18}$ Osuna, E., and Newell, G., "Control Strategies for an Idealized Public Transportation System", Transportation Science, Vol. 6, No. 1, 1972, pp. 52-72. http://dx.doi.org/10.1287/trsc.6.1.52

${ }^{19}$ Turnquist, M., and Blume, S., "Evaluating the Potential Effectiveness of Headway Control Strategies for Transit Systems", Transportation Research Record, Vol. 746, 1980, pp. 25-29.

${ }^{20}$ Eberlein, X. J. Wilson, N., Barnhart, C., and Bernstein, D., "The Real-Time Deadheading Problem in Transit Operations Control", Transportation Research, Vol. 32, No. 2, 1998, pp. 77-100. http://dx.doi.org/10.1016/S0191-2615(97)00013-1

${ }^{21}$ Ding, Y., and Chien, S., "Simulation of Bus Operations with Enhanced CORSIM: Case Study: Bus Route \#39 of New Jersey Transit”, 79thTransportation Research Annual Meeting, 2000.

${ }^{22}$ Ding, Y., "Improving Transit Service Quality and Headway Regularity with Real-Time Control", Transportation Research Board 80th Annual Meeting, January 7-11, 2001. Washington, D.C.

${ }^{23}$ Johnson, N.L., Kotz, S., and Balakrishnan, N., Continuous Univariate Distributions, Wiley, New York, 1994.

${ }^{24}$ Bureau of Infrastructure, Transport and Regional Economics, TrainLine 1, Statistical Report, BITRE, Canberra ACT, 2012. 